\title{
INTEGRATING REFUGEE CHILDREN INTO A HOST COUNTRY COMMUNITY
}

Ekaterina Zvereva, PhD in linguistics frakatr@yandex.ru

Kamo Chilingaryan, Associate Professor chili1@ yandex.ru

\author{
RUDN University, (Peoples' Friendship University) Moscow, Russia
}

\begin{abstract}
Modern society develops in complex geopolitical conditions, characterized by the processes of globalization, ethnic and religious conflicts, outbreaks of xenophobia and extremism, manifestations of various forms of violence and terror. Migration processes in the modern world are intensifying, the number of refugees, forced due to ethnic and religious conflicts to move to other countries, is growing.
\end{abstract}

In the last decades of the 20th century and the beginning of the 21st century, the problem of preparing people to live in a multinational society in the environment of increasing multinationalism and multiculturalism is the focal point of pedagogy. The challenges of modern multinational society are reflected in the ideas and practice of multicultural education, which is designed to prepare future citizen to live and work in new conditions that require a multicultural personality. Modern society must develop in the framework of multiculturalism when the equality of all cultures is recognized, tolerance for cultural diversity and differences are cultivated, racism, totalitarianism, and any discrimination based on national, religious, sexual and other grounds are completely excluded. Regardless of the strategic choice, one should be prepared for the influx of foreign migrants to increase significantly. In this regard, the country faces the problems of new challenges associated with the influx of people from other societies, other traditions, and culture of interethnic interactions. The focus of Russia's migration policy shifts to the socio-cultural sphere: the issues of socialization and language adaptation of immigrants their children acquire special significance.

The relevance of the work is due to an increase of migration influx, including migration for educational purposes. Migration flows are changing not only quantitatively but also qualitatively; there is an increase in family migration, which requires both the employment of adults and the continuation of their children in various educational institutions. Given the complicated demographic situation that affects the number of potential applicants; international educational migration can be considered as the intellectual potential of the host country. The initial preparation of migrant children to continue their studies in Russia in the "infant school-school-university" structure is crucial.

As an object of research, the authors consider strategies for developing concepts for short-term and longterm policies and a set of measures aimed at adapting and integrating the children of migrants in various countries of the world and the entities of the Russian Federation within the framework of migration policy. The aim of the study is to analyze international experience and the current situation in education; to consider the contemporary migration policy of the Russian Federation in the language aspect; to reveal its features; to analyze the existing general laws in the field of migration policy, as well as their implementation in various regional educational projects; to analyze the effectiveness of migration policy in education, and to offer some recommendations on the organization of the educational process aimed at language socialization and cultural integration of migrant children

The novelty of the research is determined by the relevance of the issues of linguistic and sociocultural adaptation of children in preschools, schools, and students at both secondary schools and universities in the new intercultural environment.

The research methodology rested on the empirical approach and used interviews as the primary tool for analysis; the theoretical analysis of the psychological and pedagogical literature on the studied problem; comparison; synthesis; systematization; questioning the reference groups of informants; quantitative and qualitative analysis of the data obtained, mathematical statistics method.

For the identification of the problems, related to the education of children of migrants, a survey was conducted among the teaching staff of schools in Moscow. Based on the Nekrasov Library (Moscow) a survey of migrants and their children, as well as the teachers, working with them was carried out. The survey also included dwellers of several districts of Moscow city. The results of the survey were processed by the 
method of mathematical statistics. As a result of the survey, the following problems were revealed: lack of knowledge of the Russian language and Russian national characteristics by migrant children, which brings further psychological and behavioral problems to migrant children. The results confirm the long-term observations of migrant children by their teachers; help determine the degree of readiness of teachers to work in poly-ethnic schools; determine the necessary measures to support both children and staff working with migrant children. The conclusions are formulated about the insufficiently developed methods of teaching and adapting children of migrants, recommendations on language and sociocultural adaptation of both children of migrants and their parents are given. Attention is drawn to the need for teacher training to work with migrant children. The results of the study emphasize the need for interdisciplinary, first of all, humanitarian approaches to the problem under consideration.

A conclusion was drawn that it is necessary to improve the legal and regulatory framework related to financing, to find new ways of interaction between the school and the system of additional education and culture, the family, guardianship, and trusteeship bodies, internal affairs, the Federal Migration System, public ethnic associations, and others. In other words, it is necessary to have a managerial will to build a new system of relations of the educational institution, which itself cannot solve a set of complex problems that go beyond its competence with other structures.

Keywords: language socialization, migration policy, multicultural education, Integration of migrants, language and sociocultural adaptation, national characteristics, migrant children

\section{INTRODUCTION}

In today's global world, international migration flows, which are a complex and multidimensional phenomenon, are becoming increasingly important. They have many characteristics and different directions, one of which is educational migration, associated with the internationalization of education and the demand for highly qualified personnel.

The processes of globalization result in multiculturalism. In light of the changes in the world, the problem of living in a multinational society is becoming the focal point of pedagogy.

Modern society is developing in the condition of multiculturalism when the equality of all cultures is recognized, tolerance for cultural diversity and differences are cultivated, racism, totalitarianism, and any discrimination based on national, religious, sexual and other grounds are considered to be completely excluded. Regardless of this, one should be prepared for the influx of foreign migrants to increase significantly. In this regard, the country faces the problems of new challenges associated with the flow of people from other societies, other traditions and culture of inter-ethnic interactions.

The most significant indicator in this regard is the reduction in the number of labor resources: according to the latest forecast of the Federal Statistics Service in 2010-2030 with a reduction in the total population by 2.8 million, the working-age population will decrease, according to the "medium variant" - by 12.1 million people. [1]. Particularly, critical the situation was in 2012-2017 when the working-age population has been decreasing by more than one million people annually. The scarcity of labor resources cannot be mitigated by measures of demographic policy (the results of which, under the most favorable conditions, will only affect after 2025, when the generation of 2007-2008 take place on the labor market). According to the forecast of the Federal Statistics Service (Rosstat), the migration increase in 2011-2030 will amount to 10.5 million people according to the "high variant" and 7 million people - on the "average," which is significantly higher than today's scale [1].

Educational migration is the global intellectual capital of any separate society and associations of countries [1, p. 485]. On the other hand, one of the most challenging problems is the demographic situation in Russia, which has led to a reduction in the number of high school graduates. Today, the education system must answer the questions: what to do in a situation of demographic shortage and how to increase the number of applicants who will become the country's human potential. Therefore, the problems of migration and demography need to be addressed together. Appropriate and high-quality training of migrant children in the school system with simultaneous motivation to enter Russian universities is a full-fledged prerequisite for increasing the number and quality of applicants who can later become highly qualified human capital adapted to Russian living conditions. Russia is interested in foreigners, studying in Russia, and continuing 
here their labor or scientific activities. By carrying out a more active policy in the field of educational migration, Russia will be able to significantly increase the degree of controllability of immigrants, get an additional area of cooperation with the ex-Soviet republics, and, most importantly, acquire young citizens of related professions who know the language and are integrated into society. Moreover, even if, after graduating from a Russian university, an international student returns to his homeland, Russia will also get a positive result: the graduate will involuntarily distribute information about the quality of education in Russian universities, elements of Russian culture, and technologies [2].

It should be noted that to date one of the most important aims of the activities of state authorities in Russia is a consistent language policy that takes into account the trends of development of the Russian language not only across the country but also within the framework of particular regions, many of which are multi-ethnic. The challenges of the times are such that theoretical discussions of the problems associated with the prospects for the development of Russian and other national languages are increasingly shifting to the practical mainstream of developing the principles of language policy, language regulation and effective measures to influence the language processes that are taking place in the society. At the same time there is a growing need to use linguistic knowledge for modeling and forecasting the phenomena of the humanitarian sphere and solving issues aimed at developing the personality of a human, and harmonizing social relations with the help of language. Most researchers agree that it is the language and culture that are the primary mechanisms for the adaptation and integration of migrants in the host society. Only clearly formulated legislation, the accessibility of the cultural and educational sphere will contribute to the successful adaptation and integration of migrants. Russia is carrying out many activities in this direction intending to prevent the most acute migration crisis that, for example, European and other countries have encountered. The Russian President's message states that "We will not allow the emergence of closed ethnic enclaves in Russia with their informal jurisdiction, living outside the legal and cultural fields of the country, ignoring generally accepted norms, laws, and regulations." [2]. One of the significant steps in this area is the introduction of a mandatory integrative (complex) level exam of mastering the Russian language, history of Russia and the basics of the legislation of the Russian Federation. Thus, the leading role among the instruments of migration policy is assigned to the Russian language. In 2015, the Russian Government approved the Federal Target Program "Russian Language" for 2016-2020 as of May 20, 2015, No. 481, which aims to "ensure the efficiency and accessibility of the system for studying the state language of the Russian Federation (the Russian language) as a mother tongue; as a non-native; as a foreign; improving the conditions for the development of human and methodological potential in the field of teaching the Russian language" [3].

Besides, with the deepening integration of the educational area, it is necessary to take into account global and pan-European trends. There is a requirement of the European Union for European citizens: to have intercultural competence, which is closely related to education, and, especially, to the study of foreign languages. The goal of the language policy of the EU is not only language learning for communicative purposes, but also effective intercultural communication to ensure understanding and tolerance, respect for different cultures [3, p. 43]. Given the desire of Russian universities to cooperate with foreign universities and Russian graduates to continue their studies in other countries, as well as the desire of representatives of these countries to study in Russia, it is necessary to explore the possibilities and problems of educational migration using the example of teaching children of migrants in Russia. The purpose of this study is to identify problems arising in the education of migrant children in Russian educational institutions and to identify the main ways to solve them. The novelty of the research is determined by the relevance of studying the issues of language and socio-cultural adaptation of students in secondary schools.

The present paper aims at conducting a pilot survey of migrant children, their parents as well as the teachers regarding their views and expectation in learning Russian as a foreign language.

The research hypothesis assumes that minors, their parents, and teachers may have different opinions and goals regarding the study of Russian as a foreign language.

\section{METHODOLOGY}

The empirical case studies were based on Moscow Nekrasov library, where classes of Russian as a foreign language are conducted for migrant children, a survey of several districts of Moscow city dwellers, as well as teachers of four Moscow state schools. Acting as independent researchers, the authors first approach the 
schools where the migrant children study, and via their representatives who have sufficient language command ask them if they (migrant children/their parents) object to answer the questions of the questionnaires under the supervision of their highly respected members of the community. Meantime it was underlined that the survey would be anonymous to escape any further possible problems. The representatives of the mentioned groups were concerned about the consequences of the school authorities as well as parents of Muscovites. However, the latter concern was dismissed by the researchers.

After obtaining the oral consent of the community representatives and presenting them the sample questions, the authors got access to the migrant children and further, to some of their parents who agreed to share their concerns and visions. No names will be disclosed in this research, as it was promised when obtaining the oral consent following the Ethics.

While carrying out the survey, the authors used the following research methods:

a theoretical analysis of the psychological and pedagogical literature on the studied problem; comparison; synthesis; systematization; questioning the reference groups of informants; quantitative and qualitative analysis of the data obtained, mathematical statistics method.

The research methodology rested on the qualitative approach and used the interviews as the primary tool. The interviews were conducted during the 5-year period (2014-2018).

The respondents' target audiences included migrant children, their parents, and teachers who held language classes, as well as Muscovites whose children study together with migrant children. (1000 residents were surveyed).

There were three parallel lines of interviews with minor migrants, their parents, and teachers. As for minors, there were interviews conducted annually in groups of 10 children aged 13-16, with 50 children interviewed during the total research period.

The children were asked about the use of language outside the classroom (within their families at their home) and their purposes of learning Russian.

Taking into account that children are a group of minors, interviews were conducted among their parents. On average, over 90 parents were interviewed; several families represented a mononuclear cell (one parent).

Parents were asked about their expectations (desired results) regarding their children studies of Russian and the level of their satisfaction with classes their children attended.

Twenty teachers have been interviewed within five years. The age group of teachers was between 21 and 27 years (the Nekrasov Library). They were also teachers of four Moscow state schools, with more than $90 \%$ of female teachers of 22 to 65 years. Teachers were asked about their challenges and desired results of their professional activities.

\section{RESEARCH RESULTS AND DISCUSSION}

\section{INTEGRATION WORLDWIDE}

The issue of successful integration of migrants into the national socio-cultural space is vital virtually in every leading country of the world: the acuteness and urgency of this problem force to search for the most effective tools for its solution. Researchers of many countries have been proposing and testing various adaptation techniques over the last decade to identify their effectiveness in the long term. All studies confirm the direct relationship between the level of language proficiency and the degree of sociocultural integration.

As for the issue of socio-cultural adaptation of the children of migrants arriving in the recipient country, it should be admitted that it has also been actively developing by prominent world scholars, governmental and non-governmental organizations. Thus, the task of the Child Trends Hispanic Institute (USA) is to provide timely and substantive data-based information and recommendations to enable quality work with Latin American children, which represent a fast-growing segment of the US population (16\%, of whom $25 \%$ are children). The Institute has created and continually replenishes the database, develops new programs and assesses existing ones, thereby contributing to the development of a specialized infrastructure for Hispanic children in the US [4]. The Center of Innocenti (Italy) at UNICEF deals with problems of childhood, including studying the adaptation of migrant children in Australia, Europe (Italy, France), and others. The Center explores the possible relationship between the effectiveness of the inclusion of migrant children in a new socio-cultural environment and such factors, as the education of parents, the level of their language command of the recipient country, the material and social well-being of the family, and others. [5]. A similar study is carried out by Frank Porter Graham Institute of Child Development (University of North Carolina, 
USA). Scientists emphasize the need to take into account in adaptive projects the fact that the acculturation of migrants is always collective: parents and migrant children are jointly involved in the transition to a new social and educational environment [6]. The issue of creating an adequate educational environment for migrant children is one of the most acute. The search for new requirements for schools, educational methods, strategies for organizing out-of-class work, methods of working with the family as ways to effectively manage cultural differences are pursued by the Harvard Graduate School of Education (USA) [7]. Recommendations for successfully overcoming the problems while integrating the migrant children into the local community are also provided by the National Center for Children from Poor Families of the Meilman School of Health Management at Columbia University (USA) [8].

In Spain, the SM Fundación deals with the study of the problems of education and has, as one of its activities, the study of adaptive educational methods among children from migrant families. According to the fund, $43 \%$ of families face difficulties at school language adaptation of children, while $57 \%$ of the children surveyed associate their future with Spain and want to become active citizens of this country. The activities of the Foundation also cover educational aspects among the migrants in Latin America. [9]. The Ministry of Labor and Social Policy of Spain carries out numerous surveys on various aspects of the migration process and concludes the need to conduct more productive work in the school educational environment due to the high level of intolerance towards children who do not speak or have little knowledge of the Spanish language. [10]. Leading academic and research centers in Spain have created working research groups, the focus of which is to study the prevailing linguo-cultural situation and to find strategies that are applicable to its maintenance. We would mention Grupo FITISPos, the University of Alcala (www.ua.es.), Grupo CRIT at Jaime I University of (www.crit.uji.es/), Grupo GRETI, University of Granada (www.ugr.es/ greti / index.html). These groups form the academic Comunica network, which has branches in six autonomous communities: Catalonia: Grupo Comunidad Catalana (Universidad de Vic), Basque Country: el Grupo de la Zona Norte (Universidad del País Vasco), Castilla y León, Extremadura: el Grupo de Castilla y León y Extremadura (Universidad de Salamanca), the Canary Islands: el Grupo de las Islas Canarias (Universidad de La Laguna), Valencia: el Grupo de Alicante (Universidad de Alicante), Galicia: el Grupo de Galicia (Universidad de Vigo).

Belgian scientists and teachers, in turn, write a lot about the underdeveloped state policy in children's adaptation: the authors of the work "Immigration and Culture" in a rather sharp form argue that the children of migrants are in the role of socioeconomic and linguistic disabled "des handicaps socio-economiques in linguistiques"[11]. French research groups, in particular the scientists of the University of Burgundy (Université de Bourgogne), speak of significant shortcomings in school curricula, which are dominated by the so-called principle of European centrism (L'occidentalo-centrisme), according to which all the achievements of European culture are presented as the most significant, while other cultures are not appreciated. At literature, history and geography courses in the French language, the processes of the colonial era are positively interpreted, while their negative consequences for other civilizations are not mentioned. The role of Islam, Muslim trends, and Arab world development tendencies are not sufficiently highlighted. Thus, undesirable educational gaps are being created, which migrant children replenish in other, often "radicalized" places, which subsequently leads and has already led to the formation of enclave areas. The authors would like to warn of dangerous long-term prospects, which incorrectly oriented school programs may entail. [12] According to a survey conducted by French and Belgian scientists, 15\% of school principals consider the presence of migrant children at their schools as a serious obstacle to the normal educational process and emphasize the fact that most children are not interested in learning as much as their peers from autochthonous families. All research groups agree on the need to take urgent strategic measures in the short and long term, which would change the current situation. [13] Swiss researchers dealing with this issue within the framework of the Education and Migration Commission in state educational institutions consider migrant children to be a genuine potential for the European future and appreciate the existing system of "linguistic socialization" of migrant children in public schools in Switzerland. [14]

\section{INTEGRATION: A CASE IN RUSSIA,}

\subsection{Acute problems of linguistic and sociocultural adaptation of migrant children}

The process of adaptation of migrant children in conditions of modern Russian is of a complex multi-level nature. It requires the consideration of a significant number of factors affecting it: the regional component, 
the social status, the migration trajectories of the family, the interscholastic mobility, the age of the student, adaptive ambitions, the cumulative effect of conflicts of different levels, the nature of school culture, intraschool and network interaction practices, including the Internet, ethnic, gender and subcultural specifics [15].

The complexity of the adaptation process to another ethnocultural environment is explained by the fact that ethnic culture is an experience of the survival of an ethnic community fixed in the memory by traditions. In a new sociocultural and language environment, migrants experience the processes of cultural maladjustment, loss of linguistic space, therefore the essential option of preserving their native language, traditions is the education and upbringing of migrants, refugees, and their children. The solution to the problems of the education of the migrants' children and refugees at the present stage is conditioned by a number of objective and subjective factors: the confrontation of motives, needs, interests of people, ethnic groups, ethnicgenerality, incompatibility of goals and values and norms, conflicts between ethnic groups and ethnic communities, pursuing incompatible goals and impeding each other [16, p. 19-23]. For migrant children or representatives of national minorities, intercultural education provides an opportunity for an equal start in life, while leaving the possibility of returning to the historical homeland open. The general goals of intercultural education are the personality through dialogue, conflict resolution, critical interpretation of one's own culture and tradition "as strange," through overcoming the ethnocentric attitude towards tolerance, recognizing the equality of chances for all, to conscious, responsible social behavior, and through this to mutual enrichment of all cultures that make up society. A migrant child who lives under the influence of the migrant subculture and runs into the culture of the majority every day is in a difficult crisis situation: regardless of whether his family decided to settle permanently in this country; whether it is the second and even the third generation foreigners, for the healthy development of his personality it is necessary to achieve a positive ethnic identity and, on this background, the emergence of ethnic tolerance. Here pedagogical support of the child plays a vital role in the choice of ethnic identity in the form of lessons in the native language and religion, scheduling in the content of education in the kindergarten and the school of cultural archetypes (fairy tales, songs, games). All this contributes to the development of a language of communication between children of the dominant culture and minority culture, accelerates the integration of the child into a new culture, while preventing the danger of de-ethnicization and marginalization [16, p. 1923]. Thus, the essence of adaptation is the combination of sustainability, identity) with variability (development, the achievement of new states), which is carried out at the level of methods of its interaction with the environment and the level of adaptive mechanisms.

Among the most pressing problems of migration are linguistic and sociocultural barriers that hinder the successful involvement of migrant children in various types of educational, cultural, leisure and social activities. The difficulty of incorporating into a different cultural environment, the Russian language, the lack of understanding of the norms and basic values of the culture of the Russian society, the ignorance of the characteristics of everyday life and the norms of interpersonal communication, communication difficulties with the students team and the staff, are not easily solved and are the main problems faced by the children of migrants [17, p. 80]. However, the data on the education of migrant children are contradictory. According to the St. Petersburg HSE, there were no significant differences in academic performance between foreign migrants and the ethnic majority. Teachers and school principals noted the high motivation of other ethnic children to study, their inclination to "anti-school culture." Also, according to data obtained by the St. Petersburg Higher School of Economics, a significant part of foreign ethnic schoolchildren are secondgeneration migrants. "Many of them have been born here; they are perfectly integrated. The proportion of children who have moved to Russia at average school age is generally small — about $10 \%$. It is these children that are considered to be a risk group due to the lack of knowledge of the Russian language and the complexity of its obtaining in adolescence.

Nevertheless, these children are also "very integration oriented. $72 \%$ of "foreign" schoolchildren plan to get higher education in our country. The authors of the study note that they have a robust post-Soviet heritage, in which the Russian language, even if they do not know it well, often plays the same role as English in India [18]. Unlike sociologists from St. Petersburg, Moscow researchers are convinced that migrant children are experiencing severe difficulties in learning educational programs, in socialization in the urban community. In the program "Education in the Capital", designed for 2012-2016, it was initially assumed that the children of newcomers would be concentrated in individual general education institutions. However, the more 
progressive position turned out to be that children of migrants are placed in classes with the indigenous population. The administration of Moscow is ready to allocate funds for the creation of mechanisms and technologies capable of ensuring the educational success of the children of migrants and broader integration into the culture of Moscow. They will be taught the Russian language and, in a sense, be "mixed" in schools, regardless of the social status of their parents [19].

In this field, a significant contribution to the study of the problems of migrant children is the study of G. E. Zborovsky and E. A. Shchuklina, in which the authors propose to consider the children of migrants as a unique social community that is in interaction, primarily with parents, relatives, communities peers (fellow practitioners), teachers [17, p. 83]. The authors propose a three-level model of adaptation of migrant children, including educational, socio-psychological, and cultural components. Educational adaptation means the assimilation of prescribed norms and values of school behavior, especially the inclusion of adolescents in educational and educational activities, their participation in extracurricular activities. Socio-psychological adaptation reflects the processes of interpersonal interaction with classmates, the breadth and depth of relationships that develop within a class, their harmony, and satisfaction with them. Cultural adaptation emerges as the development of students' creative abilities, their knowledge of the history and modern life of the host society, readiness to follow the cultural samples prescribed for adolescents and young people. The other side of this process is the inclusion of migrant children in the local adolescent and youth culture. It takes place against the background of the transformation of the ethnic and linguistic environment of migrants [17, p. 84]. It should be emphasized that the most significant problems in the education of children of migrants are considered to be the linguistic and sociocultural adaptation. It is because the children of migrants are poorly fluent in Russian. This problem is solved in schools most often through individual or group classes, i.e., the introduction of additional hours for language training. The creation of special classes for migrant children is also associated with several problems. First, children are representatives of different nationalities, which may require different methods of teaching Russian. It is necessary to take into account the fact that even with the successful development of oral speech, there remains a massive problem of learning writing. A significant problem lies in the absence of a widespread practice of communication in Russian, since communication in the family circle and within a particular enclave of migrants occurs, as a rule, in the national language. Secondly, the size of these classes is unstable due to the constant displacement of migrant families: children can appear and leave at any time of the school year. Thirdly, the level of knowledge of migrant children does not meet the regulatory educational standards of the Russian Federation. These problems reinforce the state of the so-called cross-cultural shock among all participants in the educational process. Poor knowledge of the Russian language leads to a more severe problem of sociocultural adaptation of migrant children in the process of learning, associated with a lack of understanding of a different culture, its semantic, value-normative features, and, consequently, the content of education. It should also be noted that in the Russian Federation, the need for knowledge of the Russian language is mandatory. Knowledge of Russian means the opportunity to get an education, social advancement, mobility throughout the country. Fluency in Russian, along with knowledge of foreign languages, is considered as a criterion of education. Moreover, the prestige of the Russian language does not require that its development occurs at the expense of forgetting the native language [20, p.10].

Among the main social and pedagogical problems of displaced people, the following should be highlighted:

social and psychological adaptation;

obtaining refugee status (displaced person);

housing problem;

the problem of employment;

differences in children's education programs;

language barrier;

long break in training activities; 
loss of personal status concerning teachers and peers,

the need to establish new role relationships, and some others.

The well-known psychologist N.M. Lebedeva, summarizing the experience gained so far, states that migrants enter into more or less long-term intercultural interaction with representatives of the dominant culture, and children and their education are one of the links of this interaction. [21].

Our study allows us to identify several groups of migrant children, depending on to what extent they adapt to new life attitudes: 1) children from Russian families who emigrated from hot spots; 2) children of other nationalities, fluent in Russian; 3) children who practically do not speak Russian.

There are some essential problems in teaching migrant children: a serious break in classes, poor knowledge of the Russian language, and disagreement of requirements [22] Migrant children, as a rule, are characterized by feelings of depression, mental instability, inability to constructively enter into contact, establish a normal dialogue with peers and adults, designate their position in the society and, in particular, in a group, the lack of simple ideas about ways of emotional self-regulation. All these above said entail inadequate protective reactions of migrant children $[17 ; 22 ; 23 ; 24 ; 25 ; 26 ; 27 ; 28 ; 29 ; 30]$

The culture and traditions of migrants cause misunderstanding and rejection among a significant part of the population. Often, children "bring" such a pre-programmed attitude from the family. However, the problem is mutual: often the way of life of the indigenous population is unacceptable for migrants, and traditions and culture are incomprehensible.

Migrants bring with them a particular culture that is perceived by the majority in society as alien and is associated primarily with language and educational problems. The pedagogical experience of most countries, hosting migrants and initially being multicultural, shows how important it is to adopt the concept of intercultural education as a principal component of education and training. In the first place, this benefits the indigenous people (or the national majority) of the country, concerned about the preservation of social stability in society.

When studying the problems of migrant children and their families in a different cultural environment, it is appropriate to identify the structural components of migration that determine the place of a migrant child in the social and educational policy of the region:

the social status of parents: migrants occupying a reasonably high position, and those who have a social status below;

national identity: migrants of the dominant ethnic group and representatives of other nations, as well as migrants of ethnically close and different communities;

the reasons that prompted to change their place of residence: migrants who leave because of ethnic tension, and those who leave for economic or other reasons;

way of migration realization: organized and unorganized; individual, independent, and others.

The study suggests that the cultural gap between migrant children and local children in some cases develops into a cultural shock. Sometimes it has length, which can be represented as a curve - then rising (delight, adoration of a new ethnic culture, desire to speak a new language), then descending (rejection of a new ethnic culture, nostalgia for their homeland, culture). The severity of cultural shock and the duration of preschooler's adaptation to the children's team are associated with two groups of factors: internal (individual) and external (group) factors. In the first group of factors, the most important is the age of children from migrant families. It needs to note that preschoolers adapt faster and more successfully than schoolchildren. Gender also influences the process of adaptation and the duration of cultural shock: girls are harder to adapt to the new environment than boys.

Internal characteristics of overcoming cultural shock include personal characteristics of children. If a child has such qualities as healthy self-esteem, extroversion, interest in people around him, desire for cooperation, 
self-control, courage and perseverance, then it is easier for him to adapt to a different environment. Motivation is crucial. The strongest is usually observed in children whose parents voluntarily moved to a permanent place of residence in another country. The situation is much worse for internally displaced persons (IDPs) who did not want to leave their homeland and did not want to get used to the new conditions of life. It depends on the motivation of migrants how well they know the language, history, and culture of the host country. The presence of this knowledge, of course, facilitates adaptation. M. Bayarmagnai points out that the first days of a child's stay in a new educational (preschool) institution, in which the Russian language is taught as a means of communication, interaction with parents, and integration of a child from a migrant family into a peer group, are especially tricky. At the same time, according to her, more than half of the teachers lack knowledge about the specifics of national education in the guest family and the specifics of the teacher's work with children from migrant families; about $40 \%$ of them are not focused on the educational problems of these families; a third - do not know the methodology of teaching migrants to the Russian language; almost half of them do not know the programs and methods for raising children's tolerance towards others. The pedagogical support, required for children from migrant families is currently insufficient. [31]

The analysis of various studies in the field of adaptation of migrants and their children in Russia makes it clear that the issue of the effectiveness of the integration of migrant children into the national community is the most important for public policy in terms of national security, health, and education, economic and social well-being. In this regard, when organizing the work with foreigners, it must be remembered that children from migrant families are either potential citizens of the Russian Federation or foreign citizens who in the future will "popularize the Russian language, education, culture of Russia" in their country, which "will contribute to strengthening the Russian influence, formation of a positive image of the country abroad, the increase of its international authority and eventually, the protection of Russia's geopolitical interests" [3]. We would like to mention that in Russia they release online edition of the "Migrant's Messenger," which highlights various legal, social, cultural aspects of the life of migrants, as well as new legislative acts. One of the sections of the Bulletin is dedicated to children. In it, migrants can receive any advice on financial aid, medical care for children, their admission to pre-school, and school institutions. In the same section, the views of the migrant children about their life in the Russian Federation are told. All children underline their desire to learn Russian, get acquainted with Russian culture, and become citizens of the Russian Federation. [32].

Addressing the issues related to the integration of children from migrant families into the Russian educational environment is one of the directions of the Federal Targeted Program for the Development of Education for 2016-2020. [33] Within the framework of this program it is proposed to implement projects in various regions of Russia under the title "Technologies for Language and Cultural Adaptation of Children of Migrants from CIS Countries", which is a complex of activities in the field of creating and developing "modern mechanisms and technologies of general education" and implementing adaptive educational programs. At the same time, the Program notes that it is essential to support schools in the CIS and other states that teach in Russian, including support for teachers, assistance with textbooks, material resources. It is necessary to create a system of international school Olympiads in the Russian language. Their winners and prize-winners should receive the right to enroll in the leading universities of the country: thus, a global character should be given to high-quality education in Russian. The main objectives of the project are as follows:

1. Organization and holding of regional Olympiad at the Russian language, Russian culture, and culture of migrant children;

2. Conducting open lectures ("Sunday schools") at the Russian language, Russian literature, and culture for migrant children;

3. Release of two manuals - for parents - migrants and their children, promoting quick integration of children - other language speakers into the Russian socio-cultural environment;

4. Conducting refresher courses for teachers of secondary educational institutions, working with heterogeneous, multi-ethnic groups. 
Undoubtedly, the approaches to the implementation of such a project should be comprehensive, since the process of integration of migrant children is multifaceted and multistage and means involving of all participants of the educational process - teachers, students, parents. Various regions of the Russian Federation put forward their initiatives to organize the adaptive process. As an example, in 2017 based on the Tyumen State University the Sunday school, "We are Together!" started its work for the children of migrants and their parents. [34] All meetings take place in the format of interactive sessions using innovative techniques (staging technique, simulations, project case, mastering online courses, computer testing, slow reading techniques and development of critical thinking through reading and writing) that contribute to successful mastering of necessary communicative competencies by trainees which in turn allows the childnewcomer to successfully interact in a new cultural and social environment, develop the skills of effective communication and thus, decrease the risks of academic failure. This project is called "Bilim." [35] In the Volgograd region, historically one of the most multi-ethnic and migrant-intensive regions in Russia, the Center for the Adaptation of Migrants and their Children, "House of Friendship," was opened. [36] It operates in close cooperation with national public associations of the Volgograd region, as well as with higher educational institutions, in particular, with Volgograd State University. Within the framework of the program for adaptation of migrant children in the scientific and educational center of the Institute of Philology and Intercultural Communication, a working group has been established to develop educational and methodological packages for additional classes on the study of the Russian language for migrants.

In the Nizhny Novgorod region, the Privolzhsky Migration Center was set up based on the Interregional Charitable Non-Governmental Organization (ICPO), where not only consultative but also educational, leisure and socio-legal services are provided on a free-of-charge basis. [37]

The authors have questioned 1000 Muscovites in Mitino and Khoroshevo-Mnevniki districts of Moscow. While analyzing and calculating the results, the following picture was revealed:

A survey of Muscovites with children under age revealed a relatively wide prevalence of schools in Moscow with migrant students. 35\% of Muscovites surveyed indicated joint education of their children with migrant children. In kindergartens, $18 \%$ of the respondents were children with migrant children. The children of migrants from Azerbaijan, Armenia, and Georgia (22.6\%) and internal migrants from the North Caucasus $(11 \%)$ most often study at schools. The same groups of children are allocated in kindergartens, with the only difference being that children from the Transcaucasian countries are leading (12\% of mentions), and children from Central Asia follow them (8\%). A third of migrant families with pre-school children and living with them in Moscow, visit children's pre-school institutions. About three-quarters of the children of school-age migrants attended school. Foreign migrants whose children attend schools are divided almost equally - one part considers the relationship healthy, the other - not very good.

According to the respondents' estimates, the level of the acuteness of the problems of relations between migrants and non-migrants in the school, their degree of complexity, multidimensionality is often underestimated and hushed up by the teachers. They are not always inclined to reflect on this, building interpersonal relations with students of migrants. Faced with the situation of ethnic conflicts, they do not fully understand the depth and nature of the conflict: they are looking for ways to optimize the relationships between students, sometimes without sufficient resources (cultural, intellectual, organizational, methodological, and others). Often teachers do not realize that the problems of interaction between children of migrants and non-migrants, who have gone "inside," are disguised, become underlying causes of many random acts and manifestations in the relations between children at schools, as well as between students and teachers.

\begin{tabular}{|l|l|l|}
\hline Attractive features & Irritating features & Threatening features \\
\hline Goodwill, friendliness & Aggressiveness & Too many of them \\
Kindness & Insolence & Sometimes dress up like \\
Sociability & Imposing others to your point & terrorists are scared \\
Sense of humor & view & Threaten \\
\hline
\end{tabular}




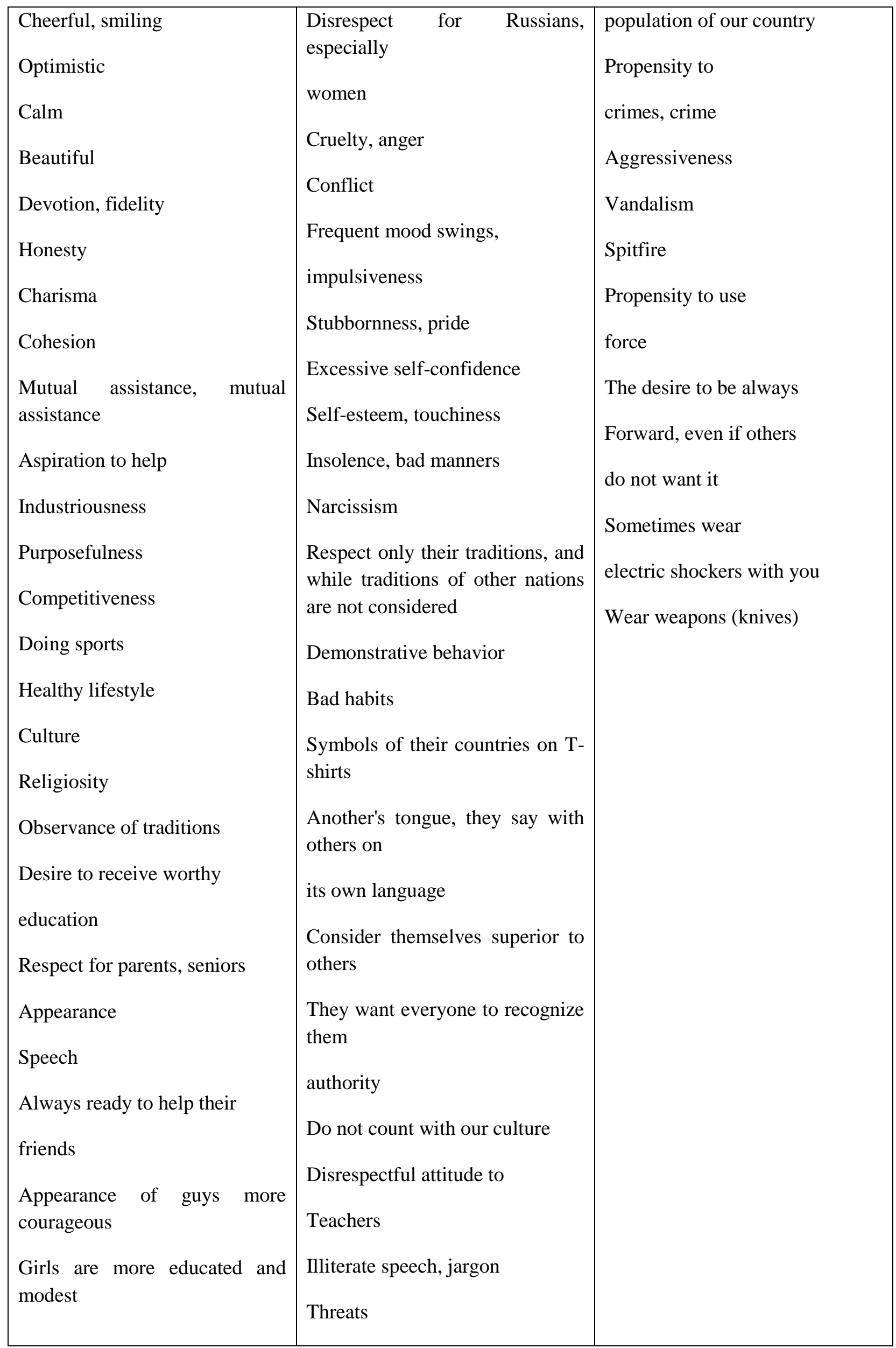




\begin{tabular}{|l|l|l|}
\hline Good workforce & $\begin{array}{l}\text { Strongly pay attention to their } \\
\text { religiosity }\end{array}$ & \\
\hline
\end{tabular}

Table 1. Social portrait of migrant children, "drawn" by students - representatives of indigenous people

In Moscow, based on N. Nekrasov library, classes are conducted in Russian and English with migrant children. [38] Within 5 years, the authors have conducted a study aimed at identifying the characteristics of cultural and language adaptation of migrant children and creating a program of promising practices for subsequent application in various educational centers. The study was conducted annually in groups of 10 children, which amounted to 50 children per survey period.

Taking into account that children are a group of minors, interviews were conducted among their parents. On average, 90 parents were interviewed; some families represented a mononuclear cell (one parent).

In the course of a survey, it was revealed that the adaptation of migrants has two conflicting tendencies. The first tendency is the need for rapprochement with the host culture. A migrant needs to "join" the cultural and linguistic space of the new society, at least at a minimal level. The second trend is connected with the influence of national public associations. The migrant seeks to unite with his fellow countrymen in a new (non-native) society, which leads to a specific, sometimes deliberate emphasis on his nationality. In principle, the effect of the second trend can be considered regular. This trend develops as a response to that supposedly aggressive environment, into which a representative of another culture enters. The training is provided by volunteer students and young teachers from various universities in Moscow. They carry out not only language training but also organize theater plays that introduce the Russian culture and literature to children, which enables them to understand the life of the host society better.

The survey of children and parents carried out by the authors when communicating with them in the $\mathrm{N}$. Nekrasov library, allows us to conclude that lack of language proficiency and adaptation problems can be divided into several aspects: the multilingualism of language practices in the family of migrants; unjust assessment by migrants of their own level of knowledge of the Russian language; the problem of formal language education for migrant children. Multilingualism and poly-contextuality of the language practice in the family of migrants can be, on the one hand, a stimulus for developing the skills of communicative

\begin{tabular}{|l|l|l|l|l|}
\hline $\begin{array}{l}\text { Do you master the } \\
\text { language to... }\end{array}$ & $\begin{array}{l}\text { learn the } \\
\text { school } \\
\text { program }\end{array}$ & $\begin{array}{l}\text { communicate } \\
\text { with peers }\end{array}$ & $\begin{array}{l}\text { get a higher } \\
\text { education and } \\
\text { obtain Russian } \\
\text { citizenship }\end{array}$ & $\begin{array}{l}\text { get higher education } \\
\text { have a better job } \\
\text { opportunity back at } \\
\text { home }\end{array}$ \\
\hline Yes & 75.8 & 83.9 & 23 & 10 \\
\hline Rather yes than not & 14,9 & 13.7 & 42 & 8 \\
\hline Rather no than yes & 1.9 & 0.6 & 3 & 55 \\
\hline No & 3.1 & - & 1 & 8 \\
\hline Difficult to answer & 4.3 & 1.9 & 31 & 100 \\
\hline Total language & 0.8 & 100.0 & 100 & \\
\hline $\begin{array}{l}\text { Russian } \\
\text { development index }\end{array}$ & 0.9 & & & \\
\hline
\end{tabular}

Table 2. Respondents about their level of knowledge of Russian (as a percentage over the number of respondents) 
interaction between the child and his parents, and on the other hand, an absolute obstacle to mastering the spoken Russian language, since this does not create a monolingual environment. [38]. See Table 1.

We assume that the lack of permanent language practices in Russian within the family objectively hinders the language adaptation of migrants, especially of their children. The objectively existing multilingualism in family communication puts each member of the family in the situation of choosing a language code. Naturally, the one is chosen, which is traditionally adopted, and, based on our survey only $11.0 \%$ will choose Russian. It seems that this percentage can be considered correct for most regions of the Russian Federation. We believe that when moving to another country (region) with a different language environment, the family cannot be regarded as a universal basis for informal language adaptation not only of the child but also of the adult. Quite often, families of migrants deliberately try to maintain their native language as an element of national culture. Russian language in everyday communication in these cases is used locally, fragmentarily, speech practices are usually primitive, artificial, and language culture is weak.

Speaking about the self-assessment of their language command, the children-migrants evaluate their knowledge of the Russian language as high. See Table 3.

The age group of teachers is between 21 and 27 years. Twenty teachers have been surveyed within five years. Analysis of the gender characteristics of teachers showed that $30 \%$ are men, and $70 \%$ are women. The first three years of research among the teachers, there were only teachers of the Russian language (100\%). The last two years there also appeared three psychologists, one of whom specializes in resolving conflict situations. (The wishes of the parents determined the emergence of such a specialist). The survey of the teachers has allowed to conclude that the ultimate goal of studying the Russian language as a non-native language should be not only proper knowledge in the Russian language but also the formation of a shared identity. The latter is formed on the basis of knowledge about one's own culture and culture of another people; representations of the variability of traditions; from the awareness of the primacy of universal human values in comparison with ethnic values. The formation of positive (rational) ethnic identity and shared identity takes place by creating attitudes towards respect for the rights of the individual regardless of group affiliation. Within the framework of the courses on the Russian language, essential skills of understanding and interpretation, i.e. dialogue, discussion, and cooperation, from the point of view of overcoming intolerant attitudes are formed. Training in these skills should lead to narrowing of the social distance between problem groups. Table 3 shows some problems in this framework.

\begin{tabular}{|l|c|}
\hline Establishment of contact with students & 18 \\
\hline Lack of motivation and interest in learning & 12 \\
\hline Making contact with parents & 6 \\
\hline $\begin{array}{l}\text { Weak knowledge (ignorance) of the Russian language- } \\
\text { intermediary by the students }\end{array}$ & 30 \\
\hline Inhomogeneity of the ethnic composition of the collective & 13 \\
\hline Heterogeneity of the level of knowledge of Russian & 10 \\
\hline $\begin{array}{l}\text { The parents' unwillingness to be included in the educational } \\
\text { process }\end{array}$ & 9 \\
\hline Lack of uniform textbooks & 2 \\
\hline
\end{tabular}

Table 3. Problems faced by teachers. 
The teachers also noted that the most problematic group of migrant children are children from the republics of the North Caucasus (Dagestan, Chechnya) due to a different mentality. As noted by the respondents, boys from these republics "grow up quicker", "their life experience is richer," and they know more about life and everyday problems, so they often act as informal leaders in the classroom. In classes with these children, sometimes there is an unhealthy atmosphere when these children begin to terrorize the others; they tend to be arrogant towards girls. Quite often, there are conflict situations provoked by migrant children (for example, a stable orientation of some migrant boys on their gender superiority).

\begin{tabular}{|l|l|l|}
\hline The desired result & Teachers & Parents \\
\hline $\begin{array}{l}\text { Providing / receiving assistance in overcoming communicative } \\
\text { barriers arising in the process of the child's mastery of the disciplines } \\
\text { of the school curriculum (at lessons, while doing homework }\end{array}$ & 40 & 75 \\
\hline strengthening the norms of speech and social behavior & 15 & 12 \\
\hline $\begin{array}{l}\text { creation of a shared cultural background with children of the Russian } \\
\text { Federation based on studying precedent texts of Russian folklore, } \\
\text { children's literature, national animated and feature films }\end{array}$ & 20 & 7 \\
\hline $\begin{array}{l}\text { formation of a tolerant worldview in the multicultural environment of } \\
\text { Moscow }\end{array}$ & 25 & 4 \\
\hline Difficult to answer & - & 2 \\
\hline Total & 100.0 & 100.0 \\
\hline
\end{tabular}

Table 4. Survey of teachers and parents

While trying to find out the satisfaction / dissatisfaction of the parents - migrants on the level of satisfaction, the authors the following results were obtained (see Table 5):

\begin{tabular}{|l|l|}
\hline \multicolumn{2}{|c|}{ Are you satisfied... } \\
\hline with the level of education? & 42 \\
\hline psychological atmosphere? & 12 \\
\hline competence of the teachers? & 30 \\
\hline quality of materials used? & 16 \\
\hline
\end{tabular}

Table 5. Survey of parents: how satisfied are you?

The survey of parents and teachers stressed the urgency of creating textbooks for different ethnic groups, both permanently inhabiting Russia, and for children of labor migrants. At the same time, the criteria for selecting the material are of particular importance: what is culturally valuable and what is not. Nowadays, the overwhelming majority of migrant children learn the Russian language according to standard programs, without taking into account the ethnocultural specifics of their countries. Thus, before the migrant students, there is a dilemma between the desire to preserve the culture of parents and the need to fit into the allEuropean socio-cultural context. Meanwhile, studies conducted in various European countries found that ignorance of one's own language by migrants hinders the learning of the language of the host society. According to our survey, up to $70 \%$ would like their children, while learning Russian, be able to study their native language and some of the subjects (national history, culture, literature) in their language.

In order to identify real problems in the schools of Moscow, a survey of teachers and educators of preschool institutions was conducted. The survey was conducted among the teachers and educators of Moscow schools No.138, No.160, No.1251, and No.1252. The questionnaire included questions that covered as much as possible, both educational and socio-cultural issues. In total, the survey involved 1000 respondents from Moscow, of which 3.1\% are men, 96.9\% are women between 20 and 65 years old, with work experience 
from 0 to 44 years. Almost all respondents, representing the whole range of school subjects, have personal experience in teaching migrant children. The type of educational institutions was as follows: secondary school, $56.9 \%$, Lyceum $6.9 \%$, gymnasium $2.5 \%$, kindergarten $20.6 \%$, other $8.8 \%$. Of the total number of respondents, $70.4 \%$ note that the children of migrants are present in their schools and kindergartens. As a result of the survey, some problems faced by pedagogical workers were highlighted (Table 3).

As follows from the results summarized in the table, the biggest problem is inadequate knowledge of Russian $(82.6 \%)$. In the second place, a low level of training, as well as poor results in studies $(70.1 \%)$ are observed with approximately the same percentage. However, in our opinion, these three problems are interrelated, since ignorance of the language of instruction leads to misunderstanding and ignorance of the subject. Ignorance of the language and subsequent problems are also associated with such indicators as difficulties in communicating with their parents, including parents not knowing Russian (50.9\%) and unwillingness (or impossibility due to inadequate knowledge of Russian) of parents $(45,2 \%)$ to participate in the educational process. Misunderstanding of the educational requirements by parents does not contribute to establishing contacts with children or assist in the development of a particular subject. More than half of the respondents noted the absence of additional (optional) classes and the need for their introduction to increase the level of knowledge of the children of migrants $(61.4 \%)$.

Moreover, from our additional research, it appeared that these studies are primarily related to the study of the Russian language as the language of international communication in Russia. Besides, it is also necessary to work with parents. If parents speak more than one language, they can share this knowledge with their children. Experts say that children who learn a second language are more creative and better at solving complex problems, outperform single-language peers in both verbal and non-verbal intelligence testing and tend to achieve high results in standard testing [39, p. 78]. An important indicator of successful linguistic and sociocultural adaptation of migrant children is the knowledge of the national customs and traditions of the host country. According to our research, children's lack of knowledge of local traditions, generally accepted rules of behavior is noted by $39.1 \%$, and the lack of knowledge about the national, religious, and cultural norms of newcomers by the teachers even exceeds the children's level by $3.9 \%$ (43.0\%). Restlessness, bad behavior in the classroom (34.2\%) and frequent absenteeism without a good reason (26.8\%) can be explained by the peculiarities of the development of the child's psyche and the need for motivation, which is based on understanding the subject and, accordingly, interest in it, thoroughly impossible due to lack of knowledge of the Russian language in which classes are held. Thus, the experts propose to consider the children of migrants as an exclusive social community, the work with which involves a three-level adaptation: educational, socio-psychological, and cultural. At this stage, this problem is solved by schools independently. There are several problems in creating specialized classes for children of migrants: a combination of representatives of different nationalities, which may require different teaching methods; unstable classroom enrollment; inconsistency of the knowledge of migrant children with the regulatory educational standards of the Russian Federation. The most significant problems in linguistic and sociocultural adaptation in the process of educational migration are linguistic and sociocultural barriers. Even though the data obtained by various experts are contradictory, they confirm the need to study, first of all, Russian as the language of international communication in Russia. It is a significant fact, as life in a new sociocultural society implies communication, without which it is impossible to establish adequate social ties. The survey conducted among employees of schools and preschool institutions in Moscow revealed specific interrelated problems arising in the adaptation of migrant children. However, the primary problem is the teaching of the Russian language and, as a result, the lack of understanding of the norms and values of the host society.

\subsection{Experimental Activities Of Schools To Solve The Problems Of Linguistic And Sociocultural Adaptation Of Migrant Children}

The school is an essential link in the formation of interpersonal relations with representatives of various nationalities. Teachers note that understanding the peculiarities of the national culture of migrant children can help build relationships not only with them but also with their parents [17: 89]. Thus, within the framework of the sociocultural approach, it is necessary to build a specific model of teaching, first of all, Russian as the language of international communication, through which knowledge in other subjects is 
obtained. However, to build an adequate model of teaching Russian in the framework of a sociocultural approach, it is necessary to study the sociocultural context in advance, its didactically oriented analysis in a particular country and in a specific national environment, which aims to study:

- language learning situations, i.e., if a language is studied as a second language or as a foreign language;

- school or university environment: tasks and levels of proficiency in the Russian language in a particular educational institution;

- family environment: opportunities for parents to help stimulate work on the language;

- local and regional living environment (region, city, village);

- the economic situation in the society.

The basic principle of teaching the Russian language in the framework of a sociocultural approach can become the principle of a "dialogue of cultures", the purpose of which is to cultivate language tolerance [40, p.112].

It should be emphasized that respondents $(95.5 \%)$ deny the harmful effects of teaching migrant children in mixed classes (indigenous people /migrants) and, consequently, their separate education. Moreover, a high percentage of respondents (83.3\%) noted an increase in cultural diversity and adaptation (59.0\%) with coeducation. This opinion is especially valuable in overcoming stereotypes of consciousness and behavior in the "friend-foe" dichotomy when the "alien" is always perceived more negatively. According to our additional research, many teachers, especially from remote districts of the city, note that migrant children are often more disciplined and well-groomed than children from indigenous families who have social problems (for example, parents' alcoholism, and others). At the same time, when asked about the limitation of the number of children in the classroom, for whom the Russian language is not native, the answers were distributed as follows:

- no more than $2-3$ people per class $-49.1 \%$,

- $\quad$ no more five people $-10.1 \%$,

- it is not necessary to unite the children of migrants in a class with the indigenous population - $17.5 \%$. Perhaps this view is associated with specific difficulties of blended learning, which requires additional training of teachers for classes, taking into account multilevel learning. On the other hand, the need for additional classes (adaptation courses, Russian as non-native, and others) is noted by $77.1 \%$ of respondents. The data obtained correlate with the previous question of the questionnaire on the need to introduce additional (optional) classes in order to "pull up" the children-newcomers (61.4\%). Thus, an integrated approach to solving adaptation problems is needed. An essential condition for solving the problems of linguistic and sociocultural adaptation is that the school receives a multi-ethnic status, which could contribute to additional funding for the implementation of adaptation measures. $30.5 \%$ were in favor of obtaining the status of poly-ethnic schools, $19.2 \%$ were against, $50.3 \%$ were undecided. Perhaps such a decision is due to the lack of experience in forming and obtaining such a status. On the other hand, this may entail additional state and regional expenses that can attract additional equipment for these schools (for example, language laboratories and computer rooms for language teaching), additional qualifications in the field of intercultural communications by teachers and educators, psychological support for both the employees, and children and their parents. The problem of obtaining the status of poly-ethnic schools is closely related to the answers of the questionnaire of what the state should do if there are a large number of school children who come to Russia from other countries:

- whether to carry out additional funding for schools,

- organize advanced training courses,

- make additional payments to teachers, or

- provide psychological support for teachers.

As the results of our study show, the need for refresher courses $(75.8 \%)$ and the organization of psychological support for teachers (35.7\%) substantially exceed the need for additional funding (54.1\%), which indicates the high importance of these indicators for the staff of children's educational institutions. At the same time, more than half of the respondents $(57.3 \%)$ consider it necessary to introduce additional 
payment to teachers, working with migrant children. From our point of view, this is fully justified, since these children need to be devoted more time with the involvement of additional technical resources for successful mastering, first of all, the Russian language, in the shortest possible time and for carrying out adaptation measures (extracurricular activities).

\subsection{Language As A Tool}

An actual problem is also the inadequate evaluation by the migrants of their own level of the Russian language proficiency and their failure to understand the importance of the family in the formation of language culture for sociocultural adaptation and integration into the Russian-speaking environment. This fact is mentioned by many researchers [41]. Adults with an insufficient level of knowledge of the Russian language are not fully aware of this fact. A survey of parents and their children conducted by the authors showed that children are more optimistic about the process of language adaptation, while, in the opinion of almost half of the parents, their children had problems in mastering the Russian language. Most children believe that they have a sufficient level of language to communicate with peers and master the school curriculum. Thus, the overestimated self-appraisal of the Russian language knowledge is objectively seen, which of course is an obstacle in the successful language adaptation not only for migrant children but also for their parents. If to speak about language education in a formal way, which should be obtained by children of migrants in the Russian schools, then the situation in Moscow schools can be called positive. Practically all children of migrants speak about the availability of additional classes and the help of teachers who played a significant role in their language education. Most of the children and their parents agree on the need for high-quality school education, which is explained not so much by the need for primary language adaptation, but by the understanding of the compulsion of knowing the Russian language as a pre-condition for the educational success of the child, increasing the effectiveness of the learning process and the orientation of parents and the child to get such education, which will make the child a full and competitive citizen of the new society.

Even with the successful development of spoken language by a child who enters the school, the problem of written speech remains serious. It should be settled through systematic and targeted supplementary training. Foreign and Russian scientists and teachers share the same opinion on the formation of classes. [13: 28]. Most researchers believe that, following the principles of inclusive education, schools should abandon the creation of classes that consist exclusively of migrant children. In the overwhelming majority of cases, teachers talk about the need to include such children in the environment of local schoolchildren in order to immerse them in a single language environment, which provides an opportunity to hear the normative patterns of the speech of the host country, the speech of peers.

\subsection{Tasks To Assist Migrants' Integration}

Thus, it should be concluded that, within the framework of strategies for the adaptation of migrant children to the school educational process, schools must undertake the following tasks:

1. to assist in overcoming communication barriers arising in the process of the child's mastering the disciplines of the school curriculum (at lessons, while doing homework);

2. to fix the norms of speech and social behavior;

3. to create a single cultural background with the children of the Russian Federation based on studying the precedent texts of Russian folklore, child's literature, national animated and feature films;

4. to form a tolerant world view in a multicultural environment of the region.

Federal Targeted Program for the Development of Education for 2016-2020 within the framework of the project "Technologies for the adaptation of migrant children in the educational environment" reserves a notable place to the formation of the personality of a teacher who has tolerant qualities and who has innovative teaching methods. In this regard, in the entities of the Russian Federation interactive training 
courses for secondary school teachers, heads of secondary educational institutions and additional education teachers working with heterogeneous children's groups are being created. The objectives of the courses are:

1. development of teachers' working skills in children's groups, heterogeneous in their ethnic composition and level of knowledge of the Russian language;

2. assistance in overcoming methodological difficulties in teaching Russian as a foreign language under the conditions of a modern school;

3. advisory work on optimization of the educational process in classes with a high percentage of childrennonnatives;

\section{4. formation of a teacher's competence portfolio.}

The courses have a severe empirical basis: considerable attention is paid to the ethnic and psychological portrait of the migrant, the analysis of Russian and international experiences in the field of integration of migrants (and especially their children) into a new socio-cultural space and the possibilities of applying the results of this experience in a regional context. Besides, language, teachers receive assistance in overcoming methodological difficulties in teaching the Russian language as a foreign language under the conditions of the modern school, meetings with representatives of governmental bodies and law enforcement agencies are also held. At the same time, courses are also a communicative platform where teachers share their achievements from their own practice - successful strategies for acculturation of migrant children, ways to involve their parents in the educational process.

One of the critical positions of the project "Technologies of Language and Cultural Adaptation of Children of Migrants from CIS Countries" is the active inclusion of migrant parents in the educational process, which gives a double social effect, manifesting itself in the activation of children and migrant parents entering the Russian sociocultural environment through their mutual involvement. In the regions of the Russian Federation various courses and seminars are held that introduce foreign parents to the peculiarities of the national educational system, inform about psychological and pedagogical ways of overcoming the difficulties associated with the adaptation of their children in the Russian school, legal ways of eliminating real, and preventing potential conflicts arising on the national soil, additional aspects of Russian school education (career guidance, circle activity, free time problem). A special emphasis is placed on the significant role of the parent as an essential participant in the school educational process, responsible for the socialization of the child and adherence to the academic discipline, prevention of deviant behavior and information security. Within the framework of the courses, there are meetings with representatives of state structures (the prosecutor's office, the Ministry of Internal Affairs, the education departments of the city and the region), where parents can submit their questions if necessary. Creation of educational manuals for children and their parents in the process of project implementation allows to speak about long-term prospects of acculturation of migrants through language.

Thus, the project "Technologies of language and cultural adaptation of migrant children from CIS countries" has undoubted relevance and social significance and is of interest for three categories of trainees: migrant parents, their children, and teachers of general education institutions. Through comprehensive work organized in these three areas, it is possible to achieve significant social effects in each region and to minimize the distance between those who study the Russian language and the Russian culture.

\subsection{Problems To Overcome}

Nevertheless, despite significant progress in the development and application of various adaptive practices and projects, it would be erroneous to consider that only foreign citizens staying on the territory of the Russian Federation should know the traditions and culture of our country. The host society should also have basic knowledge of traditions, customs, patterns of behavior of migrants, and be hospitable to immigrants. Unfortunately, in the Russian Federation cases of xenophobia are not uncommon, and there are no corresponding institutions that would allow to solve this problem in practice.

Also, in our opinion, to date there are no tools for coordinating the interests of various "actors" of the integration policy: federal government bodies, state authorities of the entities of the Federation, local governments, employers, other business structures, the host population, migrants, while there is no clear 
delineation of the competencies of these institutions, joining their powers with the corresponding funding. It is necessary to shift the emphasis of integration policy to the regional, local level, which implies the formation of real, local self-government.

Undoubtedly, the migration policy and the integration policy need a system of public control from the side of civil society, and we have to emphasize that there are currently no well-developed mechanisms for this control.

\section{CONCLUSIONS}

So, it should be concluded that at the moment, measures to promote the adaptation of migrants are at the initial stage of their implementation, require more in-depth analysis and substantial refinement. In the context of the multicultural society of modern Russia, the adaptation of migrants is a process that is carried out under the influence of a complex of sociocultural factors that exert both positive and negative influence. Analysis of adaptation problems reveals the insufficient effectiveness of the measures taken and determines the need for their improvement. Consolidation of all social institutions of the Russian society and long-term practical implementation of a set of measures aimed at solving this task will serve as conditions for the improvement of adaptation processes, the management of which requires development in the long term. This policy should be improved taking into account the linguistic and cultural specifics of different groups of migrants and from the standpoint of a scientific and legal approach to the definition of procedures and technologies for linguistic, cultural, social adaptation and integration.

The issue of a systematic approach to the social adaptation of migrant children is an essential outcome of our study. Moreover, we are not inclined to think that there is no such a system at the level of education management. It certainly exists, and up to a specific time it gave an opportunity to work effectively, but those principles and forms of the organization on which it was built no longer allow to respond to new challenges and newly emerged problems. Also, above all, those tasks that were delegated to educational institutions are not possible to decide only at their level. The school has exhausted its own reserves (financial, temporary, labor, organizational), which would allow it to solve the issues of education and adaptation of migrant children in a comprehensive way. It is necessary to improve the legal and regulatory framework related to financing, to find new ways of interaction between the school and the system of additional education and culture, the family, guardianship, and trusteeship bodies, internal affairs, the Federal Migration System, public ethnic associations, and others. In other words, it is necessary to have a managerial will to build a new system of relations of the educational institution, which itself cannot solve a set of complex problems that go beyond its competence with other structures. It is advisable to start with the creation of: information database (demographic statistics on migrants, statistics of child migration for educational institutions, statistics on the support to schools, developing a methodological framework, conceptual apparatus, the results of a representative study of the problems of schools, and others); methodological base; the system of training and retraining of teachers; the system of interrelation between schools and additional education for migrants, schools and cultural institutions that are oriented towards solving the problem of socio-cultural adaptation of migrants; information exchange systems for the management of education and the Federal Migration Service, the Department of Education and the internal affairs agencies.

In the current demographic situation, migrant children can be considered as part of educational migration and in the future as potential applicants to Russian universities with the possible potential of highly qualified specialists for Russian enterprises. For a successful linguistic and sociocultural adaptation of migrant children and the motivation of future migrant applicants, several measures are necessary at the schooling stage and, possibly, pre-school education.

According to a sociological survey of teachers and preschool institutions, the most significant problem when working with children of migrants and their parents is the lack of knowledge of Russian as the language of international communication. As a result, there are several problems in mastering the subjects of the school, absenteeism with insufficient motivation, the impossibility of establishing contact with parents. In this situation, specific educational work is needed to clarify the opportunities that can be obtained in Russia with excellent command of the Russian language: education, social advancement, mobility across the country. It should be emphasized that the knowledge of the Russian language does not require forgetting the native 
language. An additional problem is the ignorance of the Russian national customs and traditions, cultural norms by the children of migrants, as well as ignorance of the traditions of other cultures by the teachers themselves. This way, intercultural communication at the level of the participants of the pedagogical process is disrupted. When studying foreign languages, including Russian as a foreign one, there are severe sociocultural problems. Therefore, the analysis of the socio-cultural component of the language education deserves special attention, and the training from socio-cultural positions appears to be the most effective model for the formation of a foreign language personality as a subject of the dialogue of cultures. To build an adequate model of teaching migrant children, it is recommended to use a sociocultural approach, taking into account the national context of a particular country, on the one hand, and the level of education (school or university level), goals and objectives of a particular educational institution, on the other hand. It is also possible to use the family environment, i.e., parental assistance to stimulate language learning or family education for parents and children. Therefore, an integrated approach is needed to solve the problems of linguistic and sociocultural adaptation of migrant children through Russian language training and intercultural communication, including educational work; the introduction of additional classes (adaptation courses, Russian as non-native, psychological support, and others) not only for students and their parents, but also for teachers.

\section{Acknowledgment}

This publication has been prepared with the support of RUDN University 5-100 program.

\section{References:}

1. Presumptive population of the Russian Federation until the year 2030 - Moscow: Federal Service of State Statistics. 2009

http://www.gks.ru/wps/PA_1_0_S5/Documents/jsp/Detail_default.jsp?category=1112178611292\&elementId $=1140095525812$

2. Message of the President of the Russian Federation to the Federal Assembly of the Russian Federation of December 12, 2012: http://www.consultant.ru/document/cons_doc_LAW_138990/

3. Decree of the Government of the Russian Federation of May 20, 2015 No. 481: On the Federal Target Program "Russian Language" for the years 2016-2020:

http://government.ru/media/files/UdArRuNmg2Hdm3MwRUwmdE9N3ohepzpQ.pdf

4. Child Trends Hispanic Institute. https://www.childtrends.org/hispanic-institute/

5. UNICEF Office of Research - Innocenti: https://www.unicef-irc.org/

6. Frank Porter Graham Child Development Institute: The University of North Carolina at Chapel Hill: http://fpg.unc.edu/

7. Harvard Graduate School of Education: https://www.gse.harvard.edu/

8. National Center for Children in Poverty: https://www.facebook.com/nccp.org/

9. Claves de la integración de los inmigrantes en España 2013

http://www.grupo-sm.com/noticias-sm/noticia/fundacion-sm-presenta-informe-claves-integracioninmigrantes-en-espana-2013

10. Inmigrantes en el barrio. http://extranjeros.empleo.gob.es/es/ObservatorioPermanenteInmigracion/Publicaciones/fichas/archivos/Inmi grantes_barrio.pdf

11. Immigration et culture. https://www.cairn.info/revue-courrier-hebdomadaire-du-crisp-1988-1-page-3.htm 
12. L'accueil des enfants (d') immigrés dans les écoles françaises https://tel.archives-ouvertes.fr/tel$\underline{00696486 / \text { document }}$

13. Les eleves inmigres. https://www.oecd.org/fr/education/Les-eleves-immigres-et-lecole-avancer-sur-lechemin-de-lintegration.pdf

14. 16. Les enfants de migrants: un véritable potentiel https://doc.rero.ch/record/29065/files/les_enfants_de_migrants.pdf

15. http://vmestemy.ru/news/17

16. Gulyayeva, A. (2010), Sociocultural adaptation of migrant children. (Electronic journal). Psychological Science and Education, №5. pp.158-166.

17. Zborovsky GE, Shchuklina EA (2013) Education of migrant children as a problem of their social adaptation (2013) Sociological studies. No 2. pp. 80-91.

18. Future Russians Available at: http://www.mn.ru/society/20111125/307640404.html.

19. Lessons from peaceful coexistence: http://www.mn.ru/newspaper country/20110928/305261393.html.

20. Kuprina TV, Kultan J, Kozik T, Minasyan SM (2012) "Meaningfulness of Academic Migrants' Education, Its Assessment and Modeling on IT-based Technologies. Economy of Region, vol. 12, No. 2, pp. 485-498.

21. Lebedeva NM (2010) Introduction to ethnic and cross-cultural psychology: study guide/ed. NM Lebedeva. - Moscow: Klyuch-S, 224 p.

22. Zborovsky GYe (2015) Educational and adaptation practices of migrant children in conditions of interethnic intolerance. Available at: GYe Zborovsky. Yekaterinburg. pp. 70-83. URL: http://elar.urfu.ru/handle/10995/30245

23. Gritsenko VV (2011) Socio-psychological adaptation of children from migrant families/ed. by VV Gritsenko, NE Shustova. Moscow: Forum, 224 p.

24. Goryachev YuA et al (2008) Integration of migrants by means of education: the experience of Moscow/. - Moscow: Ethnosphere Publishing House, 112 p.

25. Krugova LV (2015) Ways of overcoming the difficulties of adaptation of children of immigrants to the Russian school reality/LV Krugova, NN Malyarchuk//Scientific-methodical electronic journal "Concept". Vol. 37. pp. 131-135.

26. Mokhova LA (2016) Research of the problems of migrant children as a condition of their social and pedagogical support/ LA Mokhova, TA Spirina//World of Science, Culture, Education. No 1. p. 103 - 105.

27. Psychological assistance to migrants: trauma, change of culture, identity crisis (2002), ed. by GU Soldatova. Moscow: $72 \mathrm{p}$.

28. Silantyev TA (2007) Sociocultural adaptation of migrant children/ TA Silantyev//Bulletin of Astrakhan State Technical University. No. 3.

29. Soldatova GU (2000) Problems of adaptation of displaced people in Russia/ GU Soldatova, P A Cherkasov, LA Shaigerova//Psychologists about migrants and migration in Russia. Information and analytical newsletter. No 1. p. 9-25

30. Shaposhnikova TD (2012) To the problem of adaptation of children from migrant families in the modern sociocultural space/ TD Shaposhnikova//Primary School plus before and after. Moscow: No 5. p. 87-91.

31. Bayarmagnay M (2008) Features of the relationship of teachers and parents in the process of adaptation of a child from a family of migrants in a preschool institution Available at: M. Bayarmagnai//Knowledge. 
Understanding.

Skill.

No

4.

pp.

https://elibrary.ru/download/elibrary_11675018_79492318.pdf

32. Bondyreva, C. (2004), The other in ethnic self-determination and general cultural definition (Difference and separation, Identity and tolerance, Separation as a condition for unification) // The World of Psychology. № 3,. pp. 19-23.

\section{3. http://www.vestnik-migranta.ru/2017/04/deti-7.html}

34. Decree of the Government of the Russian Federation of May 23, 2015 No. 497: On the Federal Targeted Program for the Development of Education for the years 2016-2020: http://government.ru/media/files/uSB6wfRbuDS4STDe6SpGjaAEpM89lzUF.pdf

35. https://www.molbulak.ru/news/chaykhana

36. https://www.rusprofile.ru/id/278804

37. https://2gis.ru/n novgorod/firm/2674540559894157

38. http://nekrasovka.ru/afisha/28-03-2018/234

39. Avakyan N (2011) "On the Peculiarities of Bilingual Children's Speech Development." Armenian Folia Anglistika. International Journal of English Studies, Vol. 1, No. 8, pp. 77-80.

40. Meng X (2011) "Teaching on the Socio-Cultural Problem." Proceedings of the XII Congress of the Russian Language and Literature. Shanghai: Shanghai Foreign Language Education Press, pp.111-114.

41. Zborovskiy, G., Shuklina, E., Zasypkin, V. (2015) Educational-adaptive practices of migrant children in an interethnic situation // Izvestia Ural Federal University. Series 1: Problems of Education, Science and Culture. № 1. pp.70-83 